\title{
O estatuto do narrador e da matéria narrada no Satyricon de Petrônio
}

\author{
Sandra Maria Gualberto Braga Bianchet \\ Universidade Federal de Minas Gerais \\ sandra.bianchet@gmail.com
}

\begin{abstract}
The Satyricon of Petronius (first century a.D.) is taken as a literary work of which there is no precedent; compared to all other known works produced up to its time, it has unique characteristics. Nevertheless it reshapes many literary genres, either in prose or in verse, by means of parody, and restates a new way of making fiction: independent from inspiration by Muses, dependent on first-person narrator. It is intended here to focus on some traces of this new modus narrandi found in Petronius' Satyricon.

KEYWORDS: Satyricon; Petronius; Latin novel; parody; first-person narration.
\end{abstract}

\section{Introdução}

O Satyricon de Petrônio, obra escrita muito provavelmente na segunda metade do séc. I d.C., durante o Principado do imperador Nero, apresenta-se como uma obra de interesse tanto para os estudos linguísticos, quanto para os estudos literários.

Em termos linguísticos, sua importância se torna mais evidente, apesar de não unicamente, nos capítulos 27 a 79, referentes ao grupo de episódios conhecido como Cena Trimalchionis (o jantar de Trimalquião), que descreve eventos ocorridos na sala de jantar de um certo Trimalquião, um liberto riquíssimo desejoso de ostentar suas enormes riquezas a representantes de diferentes grupos da sociedade romana. Nessa sequência episódica, o narrador em primeira pessoa, Encólpio, não raro transfere a voz narrativa aos convivas, a maioria de baixa escolaridade, traço cuidadosamente demarcado pelo autor por meio de "desvios" morfológicos, sintáticos e lexicais, tais como problemas no emprego de caso, atribuição de gênero, marcação de tempo, neologismos, ${ }^{1}$ só para citar alguns. Dessa forma, o Satyricon pode ser tomado como fonte segura para estudo e possível datação de processos de mudança ocorridos na passagem do latim para as línguas românicas, já que apresenta um registro único e particularizado de linguagem.

Já em termos literários, o status ocupado pelo Satyricon é alvo de controvérsia. Primeiramente, é preciso destacar o fato de que o Satyricon, diferentemente das obras produzidas nos mais de trezentos anos que o separam do texto que inaugura a literatura

\footnotetext{
${ }^{1}$ Para maior detalhamento dos desvios aqui mencionados, remete-se o leitor a Bianchet, S. M. G. B. $O$ "Satyricon", de Petrônio: estudo linguístico e tradução. Tese de doutorado. São Paulo: DLCV/ FFLCHUSP, 2002.
} 
latina, ${ }^{2}$ não pode ser enquadrado na teoria clássica dos gêneros, que reserva às obras em prosa a expressão de matérias não-ficcionais, de base mais utilitária (historiografia, epistolografia, retórica, oratória); às obras em verso, por sua vez, reserva-se o discurso ficcional, voltado para o delectare (poesia lírica, épica e dramática). O Satyricon, no entanto, apresenta-se como uma obra de ficção que mescla prosa e verso. Para além de uma simples questão formal, porém, essa intercalação se presta a uma pluralidade de interpretações, que revelam a pluralidade de modelos da obra. A que gênero, então, associar essa obra diferente de tudo o que se produzira na Antiguidade até o séc. I de nossa era? Seria um romance?

A principal questão que obsta atribuir ao Satyricon a designação genérica de "romance" está relacionada ao próprio surgimento da denominação do gênero: o termo romance foi utilizado inicialmente para designar a produção literária em línguas românicas, no sentido de desfazer a dicotomia romanice loqui X latine scribere; seria, pois, uma forma de se reafirmar a autonomia dessas diversas novas línguas, provenientes da modalidade oral do latim, em busca de sua identidade, também como modalidade escrita (romanice scribere). ${ }^{3}$ Dessa maneira, a aplicação da designação romance ao Satyricon poderia ser considerada um anacronismo, uma vez que um termo surgido no século XII, sob condições linguísticas e culturais bem delimitadas, estaria sendo associado a uma obra escrita no século I d.C. Por outro lado, o fato de que o termo tenha surgido apenas no século XII seria prova cabal de que só então o romance enquanto gênero literário tenha passado a existir? Para responder a essa pergunta é imprescindível que se leve em consideração o fato de que, além de representar um novo modus narrandi, desde sua origem, o romance se apresentava como gênero narrativo ficcional, basicamente destinado ao divertimento, uma vez que a narrativa factual continuou a ser escrita em latim. Dessa maneira, se se levarem em consideração os traços do romance desde a gênese do termo sob o ponto de vista literário, chega-se sem grandes impedimentos à conclusão de que resposta à questão anterior é Não - de fato, o agrupamento genérico, o rótulo, não precede o produto literário. Enquanto concretização de um certo modo de fazer literário, o romance poderia ter surgido muitos

\footnotetext{
${ }^{2}$ Entende-se por "obra que inaugura a literatura latina" a tradução da Odisseia, feita por Lívio Andronico, no séc. III a.C. (cf. Cardoso, Z. A. A Literatura Latina. São Paulo: Martins Fontes, 2003).

${ }^{3}$ Cf. Brandão, J. L. A invenção do romance. Brasília: UnB, 2006.
} 


\section{nuntius antiquus}

séculos antes do termo pelo qual o designamos, linha de raciocínio que nos permitiria atribuir ao Satyricon, de Petrônio, o título de romance.

Entendido dessa forma, o Satyricon passa a ser um marco na literatura clássica, obra inauguradora de um gênero literário que se iria difundir profusamente pela sociedade moderna.

\section{O narrador e a matéria narrada no Satyricon}

No séc. I d.C., observa-se um sentimento de impotência, de incapacidade diante dos paradigmas. De fato, a produção literária da chamada "época de Augusto" legara grandes obras, o que teria levado à aparente saturação dos setores mais importantes da produção literária: os modelos existentes ao final da época de Augusto eram tidos como insuperáveis, perfeitos. ${ }^{4}$ Como emular a excelência, a sublimidade alcançada, por exemplo, por Virgílio em suas obras?

A resposta de Petrônio a essa inquietação se dá pela retomada dos modelos da literatura sublime por meio da paródia. O principal traço diferenciador, a principal inovação introduzida pela obra de Petrônio foi exatamente a mudança do estatuto do narrador: o Satyricon confere autoridade ao narrador, uma autoridade antes conferida às Musas, filhas da Memória e de Júpiter/ Zeus, que tudo viram tudo presenciaram e, diante de uma invocação, utilizam o poeta como veículo para divulgar fatos cronologicamente muito distantes, como no poema épico de Virgílio, que possui a seguinte invocação, imediatamente posterior ao estabelecimento da matéria do poema:

Musa, mihi causas memora, quo numine laeso,/

quidue dolens regina deum tot uoluere casus/ insignem pietate uirum, tot adire laborel impulerit. ${ }^{5}$

Ó Musa, lembra-me as causas, em razão de que divindade ofendida, ou ressentindo-se do quê a rainha dos deuses teria forçado a que um varão tão insigne pelo respeito aos deuses passasse por tantos infortúnios e fosse de encontro a tantos trabalhos. ${ }^{6}$

\footnotetext{
${ }^{4}$ Cf. Conte, G. B. The hidden author: an interpretation of Petronius's Satyricon. Berkeley / Los Angeles / London: University of California Press, 1996.

${ }^{5}$ Cf. Virg., En. I, 8-11.

${ }^{6}$ Todas as traduções de texto latino aqui citadas são de minha autoria.
} 


\section{nuntius antiquus}

No romance latino, ${ }^{7}$ diferentemente, o leitor se depara com o foco narrativo no narrador homodiegético: ${ }^{8}$ aquele que conta sua própria história, que vê tudo e que filtra a narrativa. $\mathrm{O}$ eu-personagem que vive as aventuras é o eu-narrador, cuja versão da matéria narrada se dará a conhecer:

Postquam lustraui oculis totam urbem, in cellulam redii oculisque tandem bona fide exactis alligo artissimis complexibus puerum fruorque uotis usque ad inuidiam felicibus. ${ }^{9}$

Depois que percorri a cidade inteira com os olhos, voltei a meu quarto e, tendo finalmente arrancado beijos de verdade, agarrei meu garoto com abraços apertados e gozei de desejos amorosos de causar inveja.

No entanto, o narrador do romance divide a responsabilidade da narrativa com outros personagens, principalmente ao introduzir a narração de histórias curtas, às quais se poderia chamar de "fábulas milesianas". ${ }^{10}$ Nesse contexto, o narrador dá especial destaque à transferência da autoridade narrativa a outro personagem, como, por exemplo, em Sat. 61, 5 (Haec ubi dicta dedit, talem fabulam exorsus est) - "Assim que disse essas palavras, contou a seguinte história”. O eu a partir desse ponto não é mais o eu protagonista, que assume o papel de ouvinte de aventuras alheias, assim como os leitores do romance. A narrativa é, pois, composta por eventos de que o narrador é ora partícipe da ação, ora testemunha ocular, ora ouvinte de aventuras de um outro alguém. Essa composição, à maneira de um mosaico, harmoniza esteticamente eventos e representações, em princípio, díspares.

Por conseguinte, são diversos os topoi da literatura sublime de que Petrônio se vale como modelo ao compor a narrativa do Satyricon. Pelos episódios da obra, veemse inversamente representados a grandeza da poesia épica, o tratamento dramático da tragédia, a grandiloquência da oratória. Às vezes esses grandes modelos são retomados, parodiados, plagiados sutil e indiretamente, pelo menos para leitores do séc. XXI; outras vezes, os cânones da literatura latina são copiados literalmente em contextos

\footnotetext{
7 Além do Satyricon, também a obra Metamorphoseon / Asinus aureus de Apuleio recebe aqui a designação de romance.

${ }^{8}$ Cf. Genette, G. Fiction et diction. Paris: Éditions du Seuil, 1991.

${ }^{9}$ Cf. Petr., Sat. XI 1.

${ }^{10}$ Harrison, S. J. The Milesian tales and the Roman novel. In: Hofmann, H.; Zimmerman, M. (org.). Groningen colloquia on the novel. Groningen: Egbert Forsten, 1998.Vol. IX. 
deturpados, criando-se um novo lugar para a expressividade poética de Virgílio e Horácio, por exemplo.

O principal objetivo do texto de Petrônio, pode-se dizê-lo, seria exatamente a contaminação entre as diferentes formas literárias. Petrônio efetua, a todo momento, o que poderia ser chamado de transgressão dos limites genéricos; o autor usa sua narrativa e seu narrador para falar sobre gêneros através de gêneros, discute literatura fazendo literatura.

Dessa maneira, imbricados aos episódios do Satyricon encontram-se traços dos diversos gêneros literários da Antiguidade, mormente dos elementos característicos da poesia épica virgiliana, num cuidadoso processo intertextual que deixa entrever o jogo paródico ali em processo, sem, contudo, destruir a legibilidade da história em si, a direção horizontal da narrativa. Contudo, para a adequada fruição do jogo paródico meticulosamente enredado por Petrônio, exige-se um leitor com perspicácia e conhecimento prévio dos textos objeto da paródia, capaz de não só identificar o lugar de origem do texto/ contexto copiado, mas também de compreender as inversões do novo lugar desse texto.

Fazer o papel desse leitor crítico e perspicaz, ao ler o Satyricon, representa resignificar os elementos abundantes que remetem à poesia épica na obra, que transportam o leitor para o mundo heroico de Eneias ou de Ulisses, estando este, porém, no mundo nada heroico do narrador homodiegético Encólpio.

\section{Paródias do paradigma da poesia épica}

Em linhas gerais, tem-se a correspondência entre a figura do herói (Ulisses/ Eneias/ Encólpio), alvo da ira de uma divindade que representa a parte negativa dos destinos (Netuno/ Juno/ Priapo), mas que é auxiliado por outra divindade, que representa a parte positiva dos destinos (Minerva/ Vênus/ Mercúrio).

A paródia do herói da Odisseia surge a todo momento ao longo do Satyricon, associada a diferentes personagens. Ulisses é parodiado por Gitão, o garoto tímido, o puer delicatus de Encólpio, chamado de Lucrécia no capítulo IX 5 (Si Lucretia es, Tarquinium inuenisti - "Se você é Lucrécia, então encontrou um Tarquínio"), que passa a ser arguto, esperto, no capítulo LXXIX 4, e termina superando o próprio Ulisses (Vlixem astu simillimo uicit), no capítulo XCVII 4-5, ao se esconder sob a cama para fugir do molesto companheiro Ascilto, assim como Ulisses se escondera sob o carneiro 
para sair da caverna do Ciclope. A alusão ao episódio da caverna do Ciclope ressurge no capítulo CI 7, quando o navio de Licas é comparado à própria caverna do gigante. $\mathrm{O}$ próprio narrador-personagem se identifica com Ulisses no episódio de Circe (cap. CXXVI a CXXXIX), quando assume o pseudônimo de Polieno, ou mesmo quando compara a reprimenda que faz a seu membro viril à reprimenda feita por Ulisses a seu coração - Non et Vlixes cum corde litigat suo? (cap. CXXXII 13).

Outro paradigma da poesia épica retomado no Satyricon é o das cenas de reconhecimento. Além de remeter à célebre cena de reconhecimento de Ulisses por Euricleia (Odiss. IV 149), a cena de reconhecimento de Encólpio por Licas faz lembrar os versos 155-156 do canto VIII da Eneida, quando Evandro reconhece ser Eneias filho de Anquises através de seus traços físicos [Vt uerba parentis et uocem Anchisae magni uultumque recordor! - "(ao ver-te) Lembro-me das palavras de teu pai, da voz do grande Anquises e de seu semblante!']. No entanto, no Satyricon CV 9, o traço inequívoco de reconhecimento de Encólpio por Licas, é nada mais nada menos do que seu membro viril:

Lichas, qui optime nouerat, tamquam et ipse uocem audisset, accurrit et nec manus nec faciem meam considerauit, sed continuo ad inquina mea luminibus deflesxis mouit officiosam manum.

Licas, que me tinha notado muito bem, fingindo que ele também tinha ouvido uma voz, correu em minha direção e não observou nem minhas mãos, nem meu rosto, mas, com o brilho de seus olhos imediatamente curvados na direção de meus órgãos genitais, levou sua mão atenciosa até eles (...).

Posteriormente, Encólpio e Licas invertem de posição e é Encólpio que reconhece o "amigo". Porém, no jogo paródico finamente estabelecido pelo Petrônio, assim como Encólpio não foi reconhecido por Licas senão pelo seu membro viril, Encólpio somente reconhece Licas, após o naufrágio, quando seu rosto se volta para o chão.

Em outras partes do texto de Petrônio, o autor se apropria do discurso de Virgílio, através do recurso da citação. Virgílio é citado por Trimalquião no capítulo XXXIX 3 - Sic notus Vlixes? (“É assim que se conhece Ulisses?” - Eneida II 44), com necessidade de justificar: Oportet etiam inter cenandum philologiam nosse (XXXIX 4) ("É conveniente que, mesmo durante o jantar, se cultive o amor às letras"). Trimalquião, 


\section{nuntius antiquus}

o liberto riquíssimo desejoso de ostentar suas riquezas e seus "conhecimentos", consegue lembrar-se apenas de um hemistíquio do Canto II da Eneida.

Ainda na Cena (Sat. LXVIII, 4) Virgílio é novamente citado: Interea medium Aeneas iam classe tenebat - Eneida V, 1 ("Enquanto isso, Eneias com sua armada já estava em alto-mar"). Essa é a única citação de Virgílio identificada no Satyricon, pois é seguida deste comentário:

Nullus sonus unquam acidior percussit aures meas; nam praeter errantis barbariae aut adiectum aut deminutum clamorem, miscebat Atellanicos uersus, ut tunc primum me etiam Vergilius offenderit.

Nunca nenhum som mais desagradável penetrou meus ouvidos, pois, além de sua declamação demonstrar uma rispidez que se perdia entre o elevar e o abaixar da voz, ele misturava versos atelânicos, de forma tal que, pela primeira vez, até mesmo Virgílio me desagradou naquele momento.

É possível perceber duas importantes informações nessa citação e no comentário que a segue: a importância da quantidade da sílaba, não respeitada pelo artista de rua que se propôs a recitar Virgílio e a falta de refinamento dos "novos ricos", que se encantaram com essa péssima apresentação.

Versos de Virgílio reaparecem no capítulo CXI 12 - Id cinerem aut manes credis sentire sepultos?/ Placitone etiam pugnabis amori? (Eneida IV, v. 34, v. 38-39). (“Acreditas que os restos mortais, ou os manes sepultados percebem teu sacrifício? Acaso ainda combaterás esse amor agradável?’). Essas são frases proferidas por Ana, irmã de Dido, no momento crucial do canto IV da Eneida, quando Dido resolve descumprir a jura de amor eterno ao falecido marido Siqueu e entregar-se ao amor do estrangeiro Eneias. Contexto semelhante se apresenta na história breve "A Matrona de Éfeso", narrada por Eumolpo no Satyricon, em que a viúva, obstinadamente decidida a morrer junto ao túmulo de seu marido, entrega-se aos amores de um soldado.

Por fim, no capítulo CXXXII 11, após dirigir vitupérios a seu membro viril, Encólpio se vale dos seguintes versos para exprimir a reação da parte de seu corpo, que segundo ele próprio dissera capítulos antes, estava pronta para receber as exéquias. ${ }^{11}$

${ }^{11}$ Cf. Petr., Sat. CXXIX, 1: Non intellego me uirum esse, non sentio. Funerata est illa pars corporis, qua quondam Achilles eram. - "Acho que não sou homem, não me sinto homem. Aquele famoso membro do meu corpo, com o qual outrora eu era um Aquiles, está pronto para receber as últimas homenagens". 
Illa solo fixos oculos auersa tenebat, nec magis incepto uultum sermone mouetur quam lentae salices lassoue papauere collo. ${ }^{12}$

Ela, voltada para baixo, mantinha seus olhos fixos ao chão e não deslocava sua cabeça, com esse início de discurso, mais do que os flexíveis salgueiros, ou as papoulas de hastes inclinadas.

Os dois primeiros versos copiados de Virgílio descrevem, na Eneida, a reação de Dido no mundo inferior, quando é vista por Eneias, que vai ao seu encontro e tenta desculpar-se por tê-la abandonado em Cartago. No novo lugar dos versos virgilianos, identifica-se que illa se refere à mentula ${ }^{13}$ de Encólpio, que, assim como Dido, também permanece inerte, de cabeça baixa, insensível às palavras de seu interlocutor. No entanto, enquanto a insensibilidade de Dido é comparada à dureza das rochas (Quam si dura silex aut stet Marpesia cautes - Eneida VI 471), a insensibilidade do membro viril de Encólpio é mais adequadamente comparada a "flexíveis salgueiros" e "papoulas de hastes inclinadas", o que justifica plenamente a substituição.

\section{Conclusão}

Destaca-se no Satyricon a forma pela qual a literatura sublime é apresentada ao leitor, já que essa apresentação se concretiza necessariamente por meio do narrador homodiegético Encólpio. Tal como numa imagem espelhada, o novo espaço a ela destinado inverte o papel da imitatio e, no lugar da sublimidade e da expressidade dos grandes poetas latinos da "época de Augusto", expoentes máximos da confluência do ingenium e da ars, paradigmaticamente representados por Virgílio no romance de Petrônio, tem-se a expressão do burlesco e a comicidade provocada pelo deslocamento do jogo paródico.

\section{Referências}

BIANCHET, S. M. G. B. O "Satyricon", de Petrônio: estudo linguístico e traduação. Tese de doutorado. São Paulo: DLCV/ FFLCH-USP, 2002.

\footnotetext{
${ }^{12}$ Cf. Virg., En. VI, v. 469-470; Bucólicas V 16; En. IX, v. 436.

${ }^{13}$ Mentula, -ae (f.): "pênis", "membro viril". 


\section{nuntius antiquus}

BRANDÃO, J. L. Primórdios da épica: a "Ilíada". In: APPEL, M. B.; GOETTEMS, M. B. (org.). As Formas do Épico. Porto Alegre: Movimento, 1992, p. 40-55.

. A invenção do romance. Brasília: UnB, 2006.

CARDOSO, Z. A. A Literatura Latina. São Paulo: Martins Fontes, 2003.

CONTE, G. B. The hidden author: an interpretation of Petronius's Satyricon. Bekeley/ Los Angeles/ London: University of California Press, 1996.

GENETTE, G. Fiction et diction. Paris: Éditions du Seuil, 1991.

HARRISON, S. J. The Milesian tales and the Roman novel. In: HOFMANN, H.; ZIMMERMANN, M. (org.). Groningen colloquia on the novel. Groningen: Egbert Forsten, 1998.Vol. IX.

PÉTRONE. Satiricon. Texte établi et traduit par A. Ernout. Paris: Les Belles Lettres, 1999.

PETRÔNIO. Satyricon. Tradução e posfácio de Sandra Braga Bianchet. Belo Horizonte: Crisálida, 2004.

VIRGILIO. Eneide. Introd. di Antonio La Penna, trad. e note di Ricardo Scarcia. Milano: Rissoli, 2002. 